\title{
Testing of crimp connections made on a prototype stand
}

\author{
Nikodem Wróbel ${ }^{1}$, Michat Rejek ${ }^{1}$, and Grzegorz Krolczyk ${ }^{2, *}$ \\ 1 „PRO-ZAP” Grupa Introl, Mechanical Design Department, 63-400 Ostrów Wlkp., Grabowska 47a, Poland, \\ ${ }^{2}$ Opole University of Technology, Faculty of Mechanical Engineering, 45-001 Opole, St. Mikołajczyka 5, Poland
}

\begin{abstract}
The paper presents a project of a prototype stand for making inseparable crimped joints through crimping operation, which is commonly used in the construction of heat exchangers. The joint is formed by tools in form of crimping jaws, which are considered as a punch stamp for pressing two materials into each other. In effect these two materials are mutually "crimped". This elaboration contains a case study of joints being made by the workstand. Furthermore, the paper presents an analysis of features of the joints by examining them by destructive testing: Micrography, Tensile strength test, and non-destructive testing: Leakage test. The elements to be joined have been made of aluminium 6060, which is well matched to indirectly or directly make joints for all kinds of coolers or condensers.
\end{abstract}

\section{Introduction}

Making inseparable joints for the automotive or aerospace industry, determines particular approach to design, implementation and testing of them. By approach to economy of this question, the final product with made joints shall beleakproof and of appropriate durability, at the lowest possible costs of the entire product and technological process. Economical operation of various devices strongly depends on many factors, such as process parameters or type of material $[1,2]$. Aluminum alloy is a material difficult to weld with the resistance spot welding. It is still a challenge to join the aluminum sheet and the steel sheet together [3-5]. There are many other alternatives of aluminum alloy joining such as friction stir welding [6], adhesive joining or mechanical clinching [7-9]. The method of mechanical clinching has the advantage of no damage on the sheet surface, no heat, no pretreatment procedure, etc. [10].

Selecting the method of forming joints, it is necessary to consider whether the tightness of joints shall be obtained by forming processes. the other question is whether the crimping operations are considered only as indirect step prior to the final processes as bonding or soldering. Considering the mentioned aspects, the requirements of the forces which joints must hold out should be clearly stated.

A significant difficulty in joining two materials is usually a limited space for mechanism used to crimp them, in relation to the forces necessary to be provided in order to ensure requested quality of the joint.

\section{Materials and methods}

The manufactured device is intended for forming two components, the first one in shape of pipe and second one in the shape of connecting block. The operation of crimping is performed by jaws adapted to the inner diameter of a hole of connecting block. The Figs. 1 and 2 shows the tested case of joint before the "joining" operation.
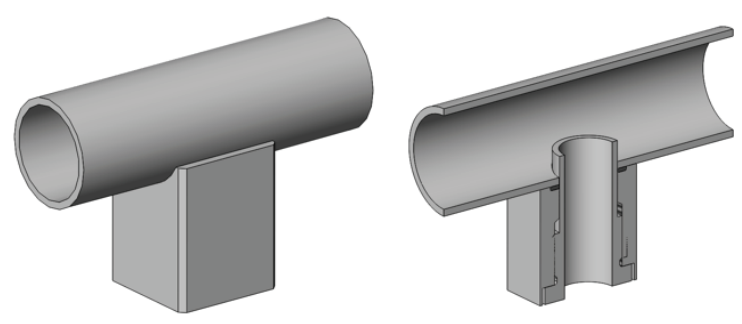

Fig. 1. View of the connecting block and the pipe.

The joint is designed to increase its durability and tensile strength force, by counteracting the torque through the locking shape of joining elements.

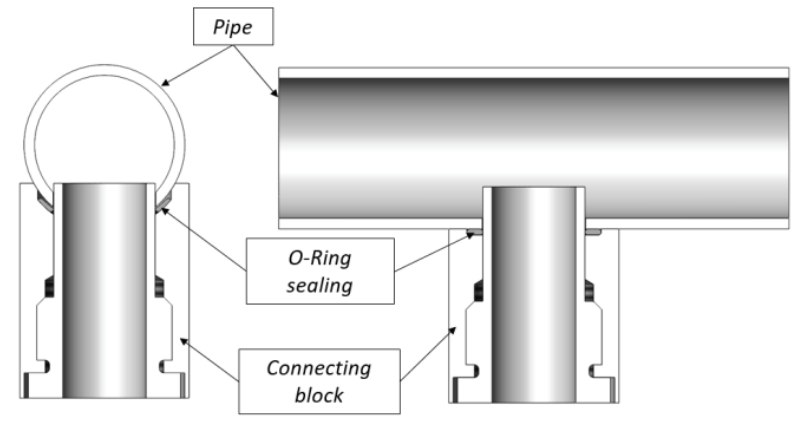

Fig. 2. View of the pipe and connecting block in two planes.

For designing process there should be assumed that between the tube and the connecting block, the jaws will spread in four directions, and their shape will be

\footnotetext{
* Corresponding author: g.krolczyk@po.opole.pl
} 
different for perpendicular cross-sections due to differences in the height of wall of hole in pipe element. Joining elements trough the forming process of the joint must be pressed against each other to compensate possible gap between them. These gaps are as a result of differences in tolerances of used components. The joint scheme is presented in three steps (see Fig. 3).
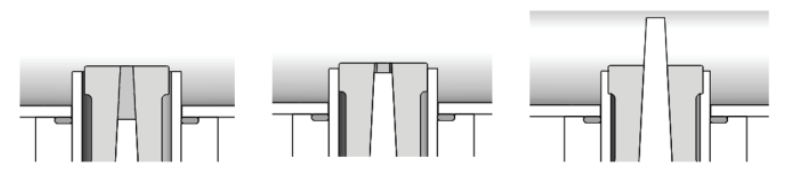

Fig. 3. Theorethical scheme of joint making proces: $1^{\text {st }}$ phase prior to jaws (no contact with components (a); $2^{\text {nd }}$ phase contact with comopnents (b), $3^{\text {rd }}$ phase - interaction of jaws into material (c)

Forming jaws in described test were made of thirdgeneration powder steel (K490) with high load carrying capacity and high impact resistance. The jaws through the applied technological processes have been hardened to a hardness of $56 \mathrm{HRC}$.

\section{Stand concept}

Designing of prototype stands involves a series of inconveniences related with requirement to fulfill defined functions of stand while maintaining the quality of a product, assure the ergonomy of the operator's work, and repeatability of process, all of above at meeting pre-established cost level.

In order to form the joint, a stand powered by pneumatic actuator has been designed, developed by a mechanical transmission, which allows to increase the forces transmitted to the system. As a consequence of used mechanism, despite of limited access to joining elements, the strength of the joint is being increased. However, application of pneumatic actuator not allows to full control of the connection making process between components, therefore it would be more accurate in further research to develop the system with electric servomotor. Nevertheless, the designed concept allows transmitting requested values of forces and executing the joint. Repeatability of forces provided to joint can be controlled by force or torque sensors and displacement sensors located on actuators or jaws.

Limited access has forced to equip the stand with mechanism of mechanical transmission in the form of wedges, manufactured on spindle spread $90^{\circ}$ apart. On each fabricated surface the jaws were guided. Applied system converts vertical motion generated by the actuator onto the horizontal motion of the punch jaws, with simultaneous transmission ratio of 1:19. The Fig. 4 shows a $3 \mathrm{D}$ view of the stand with the elements of acting and sensing.

The actor generating force is a pneumatic servomotor, which at the value of pressure medium equal to 6 bars, provides $3 \mathrm{kN}$ of force to the system makes it possible to generate a force of $18.80 \mathrm{kN}$.

The sensing part of the system consists of three sensors:
- Force sensor HBM RSCC3/2T with an RM4220 transducer, the range of 2 tons and accuracy of $\pm 0.25 \%$,

- Turck displacement sensor WIM45-UNTL-LIU5X20,3-PSG4M,

- SMC pressure sensor supervising its magnitude during the tests..

In order to collect data of the carried out tests a PC with a PC LAB transducer has been used, which allows to collect signals during the test, in the form of current values ( 4 - $20 \mathrm{~mA}$ - displacement sensor) and voltage values $(0-10 \mathrm{~V}-$ force sensor $)$.

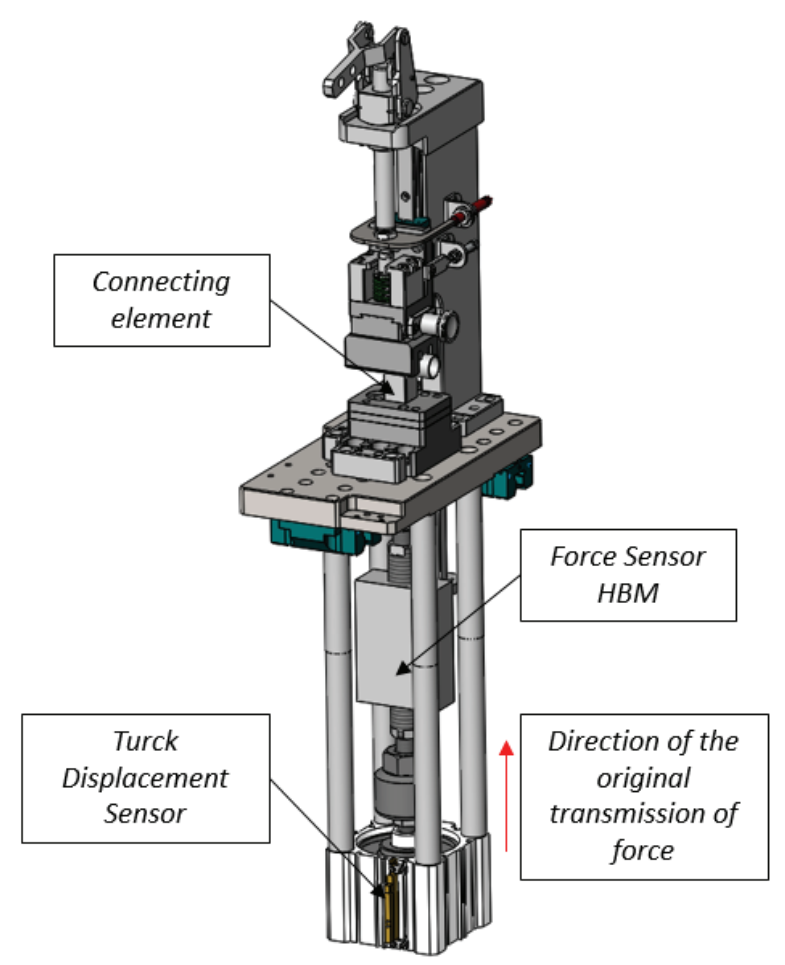

Fig. 4. View onto the main assembly of the driving machine

\section{Methodology of the experiment}

The tests have been made on the basis of six sample sets, consisting of a pipe and a connecting block each. Process of making crimped joints has been performed for two pipe diameters. Each of them has had also two values of the flange diameter, the samples have been provided equally, three with larger diameter and three with smaller one. The samples have been selected for application of sealings of o-ring form and for soldering operations. A view of the joint with the dimensions has been shown in Fig. 5 and Table 1.

In order to make the joint, 2 kinds of matched jaws to each inner diameter of pipe (larger and smaller) have been used (Tables 2 and 3).

The processing of each joint has been recorded by a data collection system. Logged values of forces required to form joint give possibility to match properly a size of used actors and designed transmission ratios.

Obtained joints can be verified by using destructive and non-destructive tests. The most common validation tests are tightness tests, endurance tests, micrographs and industrial tomography. 


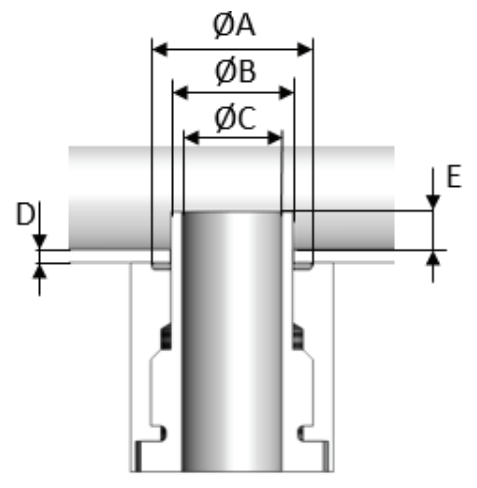

Fig. 5. Connection view with key dimensions marked on.

Table 1. Design of experiment.

\begin{tabular}{|c|c|c|c|c|c|c|c|}
\hline No & Case & ØA & ØB & ØC & D & E & O-ring \\
\hline 1 & A & $\begin{array}{l}15.8 \\
\mathrm{~h} 11\end{array}$ & $\begin{array}{c}12 \\
\mathrm{H} 7 / \mathrm{h} 6\end{array}$ & 9.9 & 1.3 & 3.7 & $\varnothing 14 \times 1.0$ \\
\hline 2 & B & $\begin{array}{l}13.8 \\
\mathrm{~h} 11\end{array}$ & $\begin{array}{c}10 \\
\mathrm{H} 7 / \mathrm{h} 6\end{array}$ & 7.9 & 1.3 & 3.7 & $\varnothing 12 \times 1.0$ \\
\hline
\end{tabular}

Table 2. Design of experiment.

\begin{tabular}{|c|c|c|c|c|c|c|}
\hline $\begin{array}{l}\mathbf{N} \\
\mathbf{0}\end{array}$ & Case & Tool & $\begin{array}{c}\text { Test } 1 \\
\text { leaktest }\end{array}$ & $\begin{array}{c}\text { Test } 2 \\
\text { Tensile } \\
\text { strength }\end{array}$ & $\begin{array}{l}\text { Micro- } \\
\text { graph }\end{array}$ & Other \\
\hline 1 & $\mathrm{~A}$ & $\begin{array}{l}\text { S1 } \\
\text { S2 }\end{array}$ & $\mathrm{X}$ & & $\mathrm{X}$ & $\begin{array}{c}\text { no O- } \\
\text { ring }\end{array}$ \\
\hline 2 & $\mathrm{~A}$ & $\begin{array}{l}\text { S1 } \\
\text { S2 }\end{array}$ & $\mathrm{X}$ & & & $\begin{array}{c}\text { no O- } \\
\text { ring }\end{array}$ \\
\hline 3 & $\bar{A}$ & $\begin{array}{l}\text { S1 } \\
\text { S2 }\end{array}$ & $\mathrm{X}$ & $\mathrm{X}$ & & O-ring \\
\hline 4 & B & $\begin{array}{l}\text { S3 } \\
\text { S4 }\end{array}$ & $\mathrm{X}$ & & $\mathrm{X}$ & $\begin{array}{c}\text { no O- } \\
\text { ring }\end{array}$ \\
\hline 5 & B & $\begin{array}{l}\text { S3 } \\
\text { S4 }\end{array}$ & $X$ & & & $\begin{array}{c}\text { no O- } \\
\text { ring }\end{array}$ \\
\hline 6 & B & $\begin{array}{l}\text { S3 } \\
\text { S4 }\end{array}$ & $\mathrm{X}$ & $\mathrm{X}$ & & O-ring \\
\hline
\end{tabular}

Tested samples were a subject of air leakage test and a tensile strength test after crimping operation, but prior to start the soldering process. The performed joints were additionally tested by micrography studies to determine the dependence of crimp action to breaking strength achieved.

Table 3. The pinching stamps used in the case study

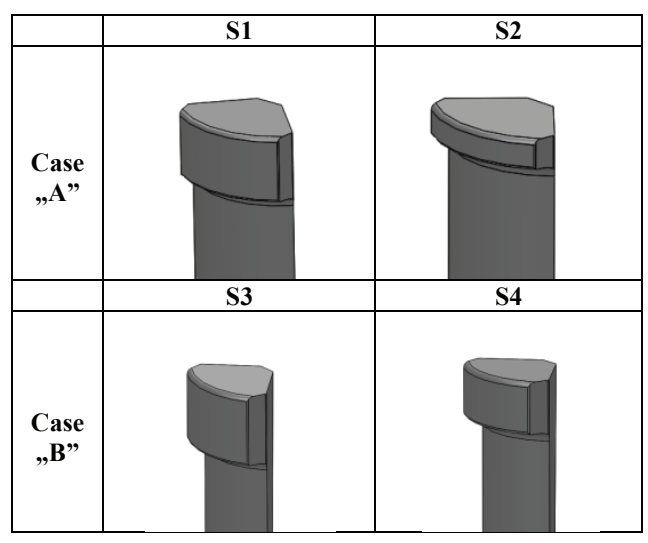

The ATEQ F520 device has been used to perform a leakage test. Two types of sample sets have been tested with O-ring and after carrying out the operations of crimping and soldering. The tensile strength test was performed on a machine based on a ball screw, along with a force and displacement sensor. To perform tensile tests in connecting block inner threads have been made and the pipes were gripped with prisms.

\section{Results and discussion}

Each sample has been a subject to an analysis of tightness. The medium pressure of leakage test was preset at $0.6 \mathrm{MPa}$, the admissible tipping point for a leakage was set at the level of $4[\mathrm{~Pa} / \mathrm{s}]$, which is the standard level of leakage for oil or water coolers in the automotive industry. Testing with air testers is affected by the temperature of the test agent as well as the sample itself, the effect on the result can also be observed against the number of consecutive leak tests for the same set of sample. The obtained results for each sample sets of the joints have met requested range of test parameters, regardless of the type of seal (O-ring, Solder). The results have been listed in Table 4 .

Table 4. Results of the connection leaktighteness.

\begin{tabular}{|c|c|c|c|c|c|c|}
\hline Test no & 1 & 2 & 3 & 4 & 5 & 6 \\
\hline $\begin{array}{c}\text { Pressure } \\
(\mathbf{M P a})\end{array}$ & 0.6 & 0.6 & 0.6 & 0.6 & 0.6 & 0.6 \\
\hline $\begin{array}{c}\text { Leakage ((Pa } \\
\mathbf{x ~ l ) / s )}\end{array}$ & 2 & 2 & 3 & 3 & 2 & 3 \\
\hline
\end{tabular}

On the basis of selected tested sample sets micrography test has been performed (Fig. 6), which allows to determine the interaction of jaws into material. The average interaction was $0.6 \mathrm{~mm}$ (dimension ,I”) per side, of which the crimping of wall of connecting block in the wall of pipe was $0.25 \mathrm{~mm}$ (dimension G). The tests and analyzes show that the alpha-angle and Ldistance have a significant impact on the strength of the joint. Higher contact point of the jaw with connecting block allows to reduce the required force, however the quality of joints is unsatisfactory.

When the punching jaws were affecting on material in bottom part of samples, the force provided by stand to the joint was not sufficient to make the joint. The thickness of wall of connecting block had also significant impact on the quality of the joint. The inner edge of the pipe either should be considered, if it is sharp, that is, with a small radius, it is easier to form the material.

Fixed joints made with native material and using cold forming processes, in the field of manufacture industry of heat exchangers are particularly exposed to pressure of the refrigerant, tensile forces and vibrations. Joining two elements by crimping operations, may be considered as the final execution of the joint, or as an intermediate operation in advance of soldering or bonding.

When crimping process is treated as an intermediate operation, joint must also be resistant to the forces and any other impact of extrinsic factor associated with the handling process. Executing joint was recorded for each of the two diameter groups, via the force sensor 
and displacement sensor.

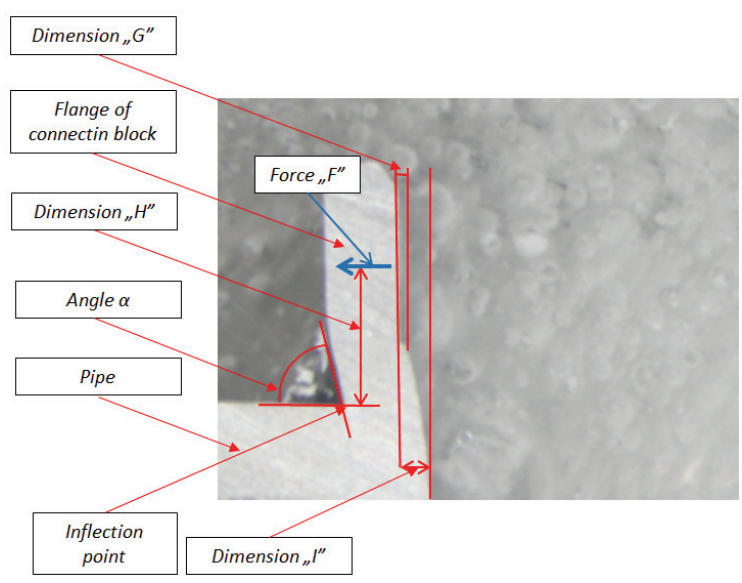

Fig. 6. Microsection of the connection

Analysis of the obtained test results is presented at the Fig. 7 and the Fig. 8.

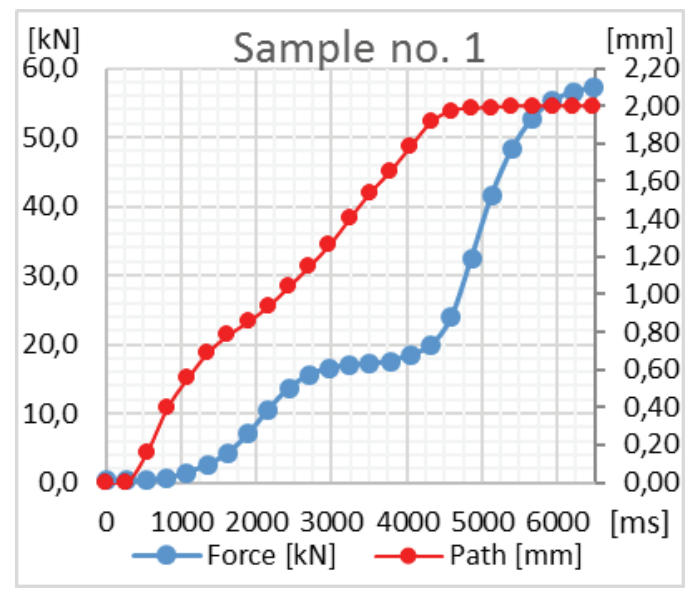

Fig. 7. Diagram of the force-at-time and force-at-path ratio for sample no. 1 .

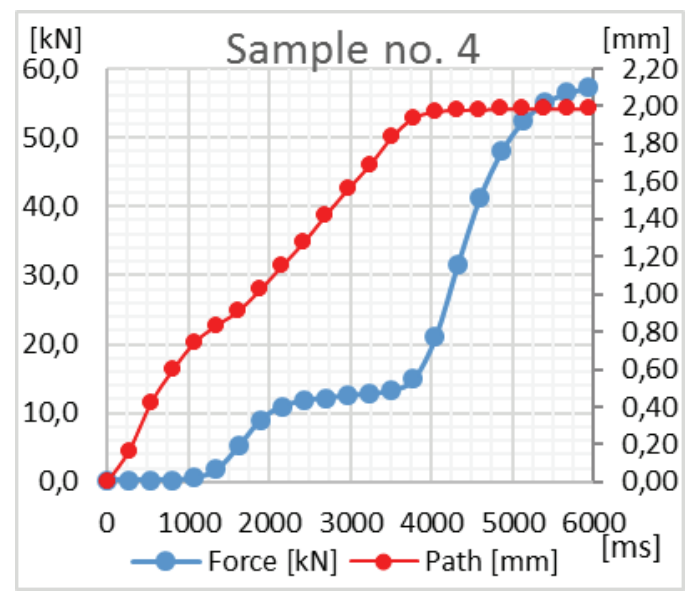

Fig. 8. Diagram of the force-at-time and force-at-path ratio for sample no. 4

The conclusion is that there is dependence between the inner diameter of the flange of connection block and the reaction force generated during the joint forming process.
The presented diagrams allow to study stages of formation the joint, as well as learning phenomenon associated with the forming process. The process is a slightly different than assumed as a theoretical one. Executed micrographs as well as analysis of data shown at charts allowed to determine first step of process, which will be defined as elimination of clearances between the jaws and inner flange of connecting block. For the first sample it is noticeable within the range of the value of force 0 to less than $1.4 \mathrm{kN}$, for the "B" test cases it is noticeable within the range of force equal 0 to less than $1.8 \mathrm{kN}$. Second step of process is defined as start of interference between jaws and inner flange of connecting block, which is connected with smoothing of the roughness and the bending of the inner flange of connection block (point of inflection occurs on the inner edge of the tube). The second step presented at diagram for test case " $A$ " is noticeable within the range of force value $1.4 \mathrm{kN}$ to $15.6 \mathrm{kN}$ and for second sample " $\mathrm{B}$ " is noticeable within the range of force value $1.8 \mathrm{kN}$ to $11 \mathrm{kN}$. The last step of the process is penetration of jaws into material with less bend of flange of connection block. Results for described step can be noticed in case of the first sample set within the range of force $15.6 \mathrm{kN}$ to $18.6 \mathrm{kN}$, for second test case within the range of force of $11 \mathrm{kN}$ to $13.3 \mathrm{kN}$. Obtained values of forces for both test cases points out that for smaller inner diameter of connecting block was less energy consuming that for larger diameter of connecting block.

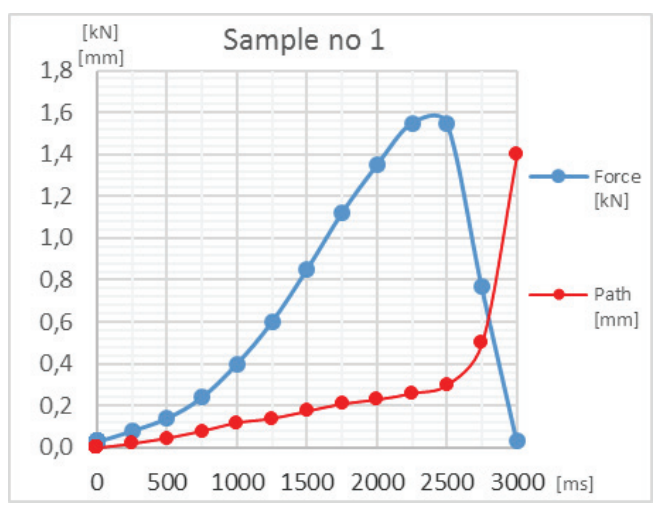

Fig. 9. Joint tensile chart depending on force applied within the requested time and the path for the sample 1.

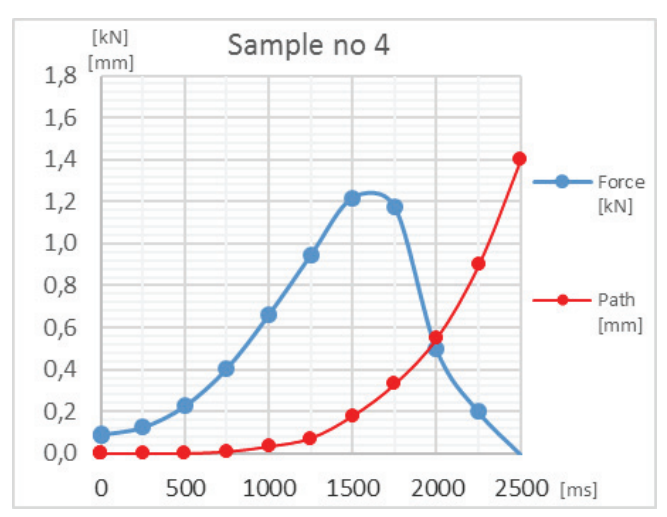

Fig. 10. Joint tensile diagram depending on force applied within the requested time and the path for the sample 4 . 
Analysis of the obtained test results for stress tests shown in Fig. 9 and Fig. 10 points out that the joint is beginning to loss his endurance and stiffness in case of test " $A$ " at $0.75 \mathrm{kN}$ and in the case of test "B" at $0.25 \mathrm{kN}$. Test samples were completely destroyed at forces of values $1.6 \mathrm{kN}$ and $1.2 \mathrm{kN}$.

\section{Conclusions}

Executed tests and studies have allowed to formulate the following conclusions:

I. The difference in diameter between cases "A" and "B" was $2 \mathrm{~mm}$, which means that the ratio of the smaller diameter to the larger one was $0.79 \%$. Transmission of this shape dependence onto the forces obtained in the various phases of joint forming was as follows:

- The first phase turned out to be less energyconsuming for the larger diameter of the connector and the difference was $0.4 \mathrm{kN}$. That means that the play ratio and movement resistance between the jaw and inner diameter in cases "A" and "B" were slightly larger in favor of the smaller diameter.

- The second phase of the joint forming, by bending and partial pressing into the material of the collar, absorbed $4.6 \mathrm{kN}$ in the extreme of this compartment for the "A" cases, what was observed as an increase by $30 \%$. The requested result for the second phase was more difficult to be achieved in case of larger diameters.

- The final phase of the joint creating of the second development was also more energy-consuming in the "A" cases. The percentage ratio of this dependence was $28 \%$, with a value of $5 \mathrm{kN}$.

Analysis of the difference in absorbed forces at different stages of joint formation shows that increasing the circumference between "A" and "B" by $6.28 \mathrm{~mm}$ while maintaining the same height of the flange has increased the needed force by $30 \%$.

II. The analysis of the joint strength showed that loosening in sample "A" occurred at a force three times lower than in the connector "B", the figure difference was $0.5 \mathrm{kN}$. Total destruction of the sample was however only at $25 \%$ greater for sample "A" than in the case "B".

III. In order to increase the strength of the joint with similar energy consumption, it is necessary to consider changing the shape of the jaws.

IV. The resulting leakage for the samples was in the correct range and did not exceed $3[(\mathrm{~Pa} * 1) / \mathrm{s}]$. Showing no difference between different type of the seals.

$\mathrm{V}$. In order to use the crimp connector as an O-ring target, with no necessity of making plans for subsequent operations, increase the applied force to produce the joint about $30 \%-40 \%$.

VI. Full control of the crimping process would be possible with a servo drive instead of a pneumatic actuator, which would allow, among other things, to control the speed of the joint creation. Unfortunately, it increased the cost of the device by $30 \%$.

\section{References}

1. R.W. Maruda, G.M. Krolczyk, P. Nieslony, S. Wojciechowski, M. Michalski, S. Legutko, J. Manuf. Process, 24, (2016)

2. G. Krolczyk, J. Królczyk, S. Legutko, A. Hunjet, Tehnički Vjesnik - Technical Gazette 21, 2 (2014)

3. C. Chen, X. Han, S. Zhao, F. Xu, X. Zhao, T. Ishida, Int. J. Adv. Manuf. Technol. (2017) (in press)

4. F. Lambiase, Int. J. Adv. Manuf. Technol. 80, 9 (2015).

5. X.C. He, Int. J. Adv. Manuf. Technol. 48, 5 (2010)

6. R. Kumar, S. Chattopadhyaya, S. Hloch, G. Krolczyk, S. Legutko, Eksploatacja i Niezawodnosc - Maintenance and Reliability 18, 1(2016).

7. J. Mucha, L. Kaščák, E. Spišák, Arch. Civ. Mech. Eng. 11, 1 (2011)

8. J. Mucha, L. Kaščák, E. Spišák, Adv. Mech. Eng. 5 (2013)

9. N. Wrobel, M. Rejek, G. Krolczyk, S. Hloch, Lecture Notes in Mechanical Engineering (2017) (in press)

10. K. Mori, T. Maeno, S. Fuzisaka, J. Mater. Process Technol. 212, (2012) 